\title{
Extraction and Nanoencapsulation of Ocimum Gratissimum Leaf Extract and Its Anti-Mycobacterial Activities
}

\author{
Sylvia Okonkwo ${ }^{1 *} \quad$ Martins Emeje $^{2} \quad$ Oladosu Peters $^{2} \quad$ Samuel Okhale $^{2}$ \\ 1.Chukwuemeka Odumegwu Ojukwu University, Uli, Anambra State, Nigeria \\ 2.National Institute for Pharmaceutical Research and Development, Idu-Karmo, Abuja, Nigeria
}

\begin{abstract}
Isolation of saponin from the methanol extract of Ocimum gratissimum leaves, its identification with HighPerformance Liquid Chromatography (HPLC), application of the saponin in the synthesis of nanoemulsion and their antimicrobial activities were carried out. $0.7 \mathrm{mg}$ was isolated from $40 \mathrm{~g}$ of powdered leaves mixed with $70 \%$ of methanol. The methanol and saponin extracts were subjected to HPLC analysis. The methanol extracts revealed 15 peaks and the saponin revealed 8 peaks with a total elution time of 30 minutes each. The saponin was used to synthesize nanoemulsion (emulsifier). The nanoemulsion and saponin were subjected to antituberculosis activity. The nanoemulsion has better anti-tuberculosis activity than the saponin due to its Minimum Inhibitory Concentration (MIC). This goes to confirm the importance of nanomedicine in the drug delivery system and its application on diverse areas such as food, cosmetics, pharmaceuticals, and material synthesis. The biological synthesis is an eco-friendly alternative to the chemical and physical methods.
\end{abstract}

Keywords: Extraction, Natural Product, Nanoencapsulation, Ocimum gratissimum, Anti-Mycobacterial, Tuberculosis.

DOI: $10.7176 / \mathrm{CMR} / 12-2-03$

Publication date: February $29^{\text {th }} 2020$

\section{Introduction}

Medicinal plants also known as medicinal herbs have been found and applied in traditional medicine practices since prehistoric time. The World Health Organization (WHO) has been coordinating a network called the International Regulatory Cooperation for Herbal Medicines to try and improve the quality of medical products made from medicinal plants and the claims made for them (W.H.O, 2017). The plant and the essential oil of Ocimum gratissimum are used in traditional medicine especially in Africa and India (Nakamura, et. al, 1999; Holets, et. al, 2003). The extracted essential oil of O.gratissimum has been reported to possess a spectrum of antifungal properties (Dubey, et. al, 2000). The blood cholesterol-lowering properties of dietary saponins are of particular interest in human nutrition (Windaus, 1909). Triterpene saponins have a list of pharmacological activities, antiulcer, analgesic, anti-allergic, sedative, anti-viral, spermicidal, and piscicidal (Hostettmann and Marston, 1995).

Development of nanoemulsions and polymer micelles-based delivery systems to achieve enhanced water solubility/dispersibility, oral bioavailability and biological benefits for phytochemicals was reviewed (Donsì, et. al, 2010). Additionally, nanoemulsion has been formulated using green synthesized silver nanoparticle from Azadirachta indica leaf extract (Ashish, et. al, 2014).

Hence, this study was conducted to investigate the anti-mycobacterium activities of saponin extracted from Ocimum gratissimum leaves and its nanoemulsion against two strains of Mycobacterium tuberculosis

\section{Methodology}

2.1 Collection of the Sample

The plant material O.gratissimum was purchased from Dei-Dei International Market Abuja of the Federal Capital Territory, Nigeria in May 2018.

\subsection{Sample Preparation}

The plant material was originally identified and authenticated by a taxonomy botanist at the National Institute of Pharmaceutical Research and Development Abuja. The plant materials (leaves) were air dried at room temperature for two weeks and grounded with a blender. The powder was packaged into a container covered with lid and store in a dry and well-ventilated room until used.

\subsection{Extraction}

The $40 \mathrm{~g}$ of grounded dry leaves were weighed in a $250 \mathrm{ml}$ conical flask. $100 \mathrm{ml}$ of $70 \%$ methanol was heated for 4 hours at $55^{\circ} \mathrm{C}$. The residue was re-extracted with $200 \mathrm{ml}$ of $70 \%$ methanol. The extract was concentrated on water bath till the volume reduced to $40 \mathrm{ml}$. the extract was transferred into a separating funnel and mixed with $20 \mathrm{ml}$ of hexane in a separating funnel. The separating funnel was allowed to stand still. There is a development of an aqueous and hexane layer. Aqueous layer portion was collected, and the hexane layer was discarded. $60 \mathrm{ml}$ of $\mathrm{n}$ butanol was added and properly mixed by vigorous shaking. The n-butanol extract was treated with $10 \mathrm{ml}$ of $5 \%$ 
sodium chloride solution. It formed a precipitate. The precipitate solution was concentrated on a water bath. The concentrated precipitate saponin was dried in an oven. The saponin precipitate was weighed (Ajuru, et. al, 2017).

\subsection{High-performance liquid chromatography analysis}

The methanol and saponin extract of O.gratissimum were analyzed by High-Performance Liquid Chromatography (HPLC) with UV Diode Array Detector (UV-DAD). The HPLC consisted of Ultra-Fast LC-20AB equipped with SIL-20AC auto sampler; DGU-20A3 degasser; SPD-M20A UV-Diode Array Detector; column oven CTO-20AC, system controller CBM-20Alite and Windows LC solution software (Shimadzu Corporation, Kyoto Japan); column, $5 \mu \mathrm{m}$ VP-ODS C18, and dimensions $(4.6 \times 150 \mathrm{~mm})$. The chromatographic conditions included mobile phase: $0.2 \% \mathrm{v} / \mathrm{v}$ formic acid and acetonitrile (20:80); mode: isocratic; flow rate $0.6 \mathrm{ml} / \mathrm{min}$; injection volume 10 $\mu \mathrm{l}$ of $100 \mathrm{mg} / \mathrm{ml}$ solution of extract in water; detection UV $254 \mathrm{~nm}$. The HPLC operating conditions were programmed to give solvent B: $20 \%$. Column oven temperature was $40^{\circ} \mathrm{C}$. No standard reference was employed for identification purpose (Okhale, et. Al, 2017).

\subsection{Preparation of O.gratissimum nanoemulsion}

Tween 80, sodium dodecyl sulfate and sodium carboxymethyl cellulose were used as excipients. A $10 \%$ concentration of cocktail-excipients in water was prepared. A $2 \%$ solution of O.gratissimum in dichloromethane was prepared and slowly dropped to the aqueous solution of the excipients that were stirred $(600 \mathrm{rpm})$. Then the system was stirred $(600 \mathrm{rpm})$ for $10 \mathrm{~min}$ at $35^{\circ} \mathrm{C}$, after which the mixtures were transferred to a shaking bath where they were mixed again for $40 \mathrm{~min}$, and the simultaneously organic solvent was evaporated and air-dried.

\subsection{Anti-tuberculosis activity of saponin and synthesized nanoemulsion (emulsifier) of Ocimum gratissimum} The anti-tuberculosis activity of saponin and synthesized nanoemulsion (emulsifier) of saponin from the leaves of O.gratissimum was carried out on Mycobacterium bovis BCG strain (ATCC 35737) and Mycobacterium smegmatis (650) using broth dilution method. These two strains of tuberculosis are acceptable as surrogates in drug research development against tuberculosis due to lack of containment of pathogenic tuberculosis. A $5 \mathrm{mg}$ of saponin and nano emulsified saponin from O.gratissimum were dissolved in $1 \mathrm{ml}$ of sterilized Middle $7 \mathrm{H} 9$ broth and 50\% aqueous Tween 80 respectively and centrifuged for 20 minutes at 13,000 rpm. $100 \mu 1$ of each of the solutions was introduced into $1^{\text {st }}$ well of a 96 -well micro-titer plate, from where a two-fold dilution was performed by transferring $50 \mu \mathrm{l}$ from $1^{\text {st }}$ well into well 2 containing $50 \mu 17 \mathrm{H} 9$ broth, with thorough mixing and repeated through to well 11 where $50 \mu \mathrm{l}$ was discarded, leaving column 12 for the negative control. A $50 \mu 1$ of inoculum prepared by diluting a 5 -7-day old culture of M.bovis BCG and M. smegmatis (OD 0.2-0.3) 1:1000 (by adding 50 $\mu \mathrm{l}$ of cell culture into $50 \mathrm{ml} 7 \mathrm{H}$ 9/ADC medium) was added to all the wells and incubated for 14 days at $37^{\circ} \mathrm{C}$. The MIC determinations were done in duplicate. Post incubation period the plates were stained by $25 \mu 1$ of 3-(4, 5dimethylthiazol- 2-yl)-2, 5 diphenyltetrazolium for color change in wells where there is no inhibition of $\mathrm{M}$. tuberculosis cells. The last well where there is no color change is regarded as the MIC of the test agents against M. tuberculosis.

\section{Result}

Table 1. High-Performance Liquid Chromatography of methanol extracts

\begin{tabular}{|l|l|l|}
\hline Retention time & Peak Area & Area \% \\
\hline 3.153 & 5573039 & 5.49 \\
\hline 3.913 & 8276049 & 8.15 \\
\hline 4.734 & 11695133 & 11.52 \\
\hline 6.265 & 9277444 & 9.14 \\
\hline 7.501 & 10621211 & 10.46 \\
\hline 8.480 & 5154479 & 5.08 \\
\hline 9.207 & 3063118 & 3.02 \\
\hline 10.469 & 2861382 & 2.82 \\
\hline 11.530 & 33840691 & 33.32 \\
\hline 14.413 & 261709 & 0.26 \\
\hline 17.179 & 6715101 & 6.61 \\
\hline 19.794 & 2208725 & 2.17 \\
\hline 22.802 & 691808 & 0.68 \\
\hline 24.702 & 423058 & 0.42 \\
\hline 27.858 & 890978 & 0.88 \\
\hline
\end{tabular}


Table 2. High-Performance Liquid Chromatography of Saponin extract.

\begin{tabular}{|l|l|l|}
\hline Retention time & Peak Area & Area \% \\
\hline 3.057 & 18909496 & 41.03 \\
\hline 3.834 & 8051052 & 17.47 \\
\hline 4.594 & 11113079 & 24.11 \\
\hline 6.283 & 2819077 & 6.12 \\
\hline 7.544 & 3527815 & 7.66 \\
\hline 11.687 & 1429325 & 3.10 \\
\hline 14.363 & 98912 & 0.21 \\
\hline 17.284 & 136168 & 0.30 \\
\hline
\end{tabular}

Table 3. Anti-tuberculosis activity of saponin and nanoemulsion (emulsifier) against M.bovis and M. smegmatis

\begin{tabular}{|c|c|c|c|c|c|c|c|c|c|c|c|c|c|}
\hline \multirow[b]{2}{*}{ Samples } & \multirow{2}{*}{$\begin{array}{l}\text { Starting conc. } \\
\mu \mathrm{g} / \mathrm{ml}\end{array}$} & \multicolumn{12}{|c|}{ Micro well plate } \\
\hline & & 1 & 2 & 3 & 4 & 5 & 6 & 7 & 8 & 9 & 10 & 11 & $\begin{array}{l}\mathrm{MIC} \\
\mu \mathrm{g} / \mathrm{ml}\end{array}$ \\
\hline $\begin{array}{l}\text { Saponin } \\
\text { Against } M . \text { bovis BCG }\end{array}$ & 5000 & - & - & - & + & + & + & + & + & + & + & + & 1250 \\
\hline Saponin against $M$. smegmatis & 5000 & - & - & - & - & + & + & + & + & + & + & + & 625 \\
\hline $\begin{array}{l}\text { Saponin (emulsifier) against } \\
\text { M. bovis BCG }\end{array}$ & 5000 & - & - & - & - & - & + & + & + & + & + & + & 312.5 \\
\hline $\begin{array}{l}\text { Saponin (emulsifier) against } \\
\text { M. smegmatis }\end{array}$ & 5000 & - & - & - & - & - & - & - & - & + & + & + & 39 \\
\hline
\end{tabular}

KEY: - = Activity, no growth, $+=$ Growth of organisms.

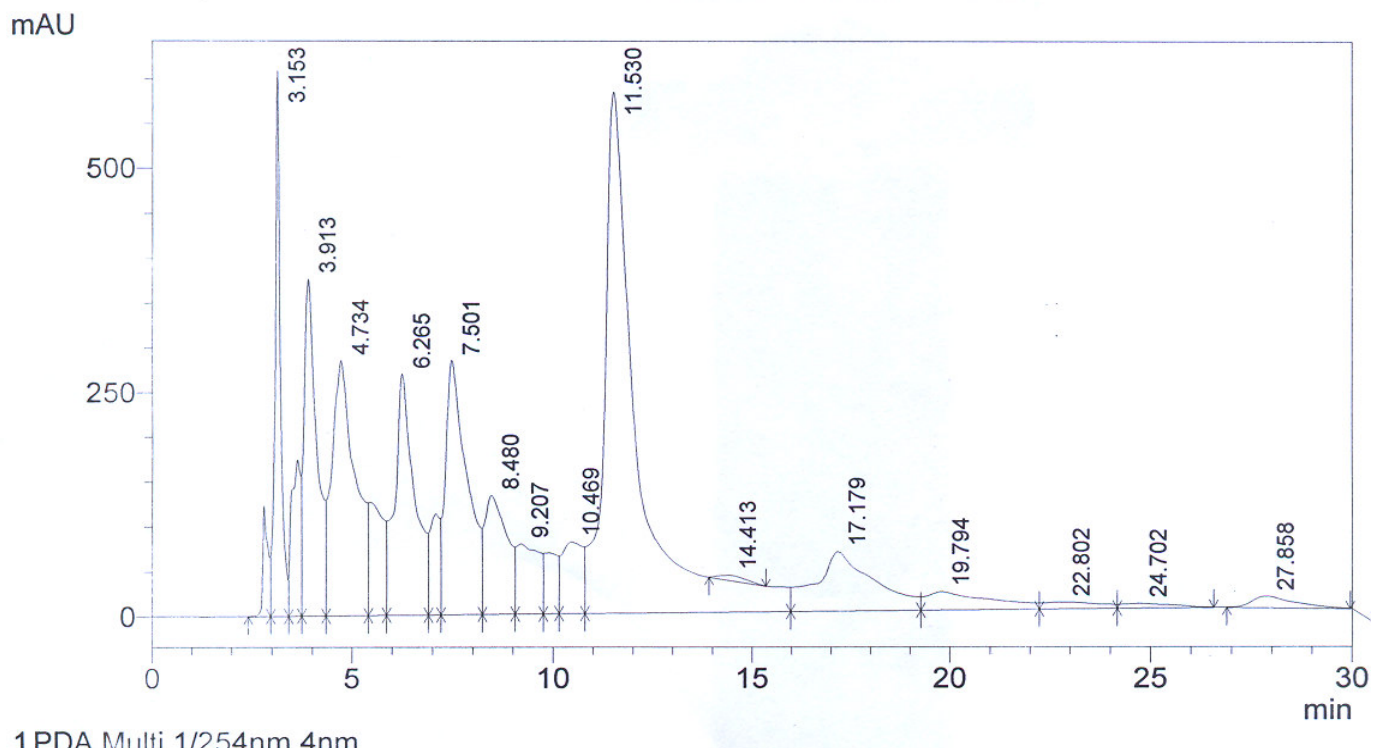

1 PDA Multi $1 / 254 \mathrm{~nm} 4 \mathrm{~nm}$

Figure 1. HPLC spectrum of methanol extract of O.gratissimum 


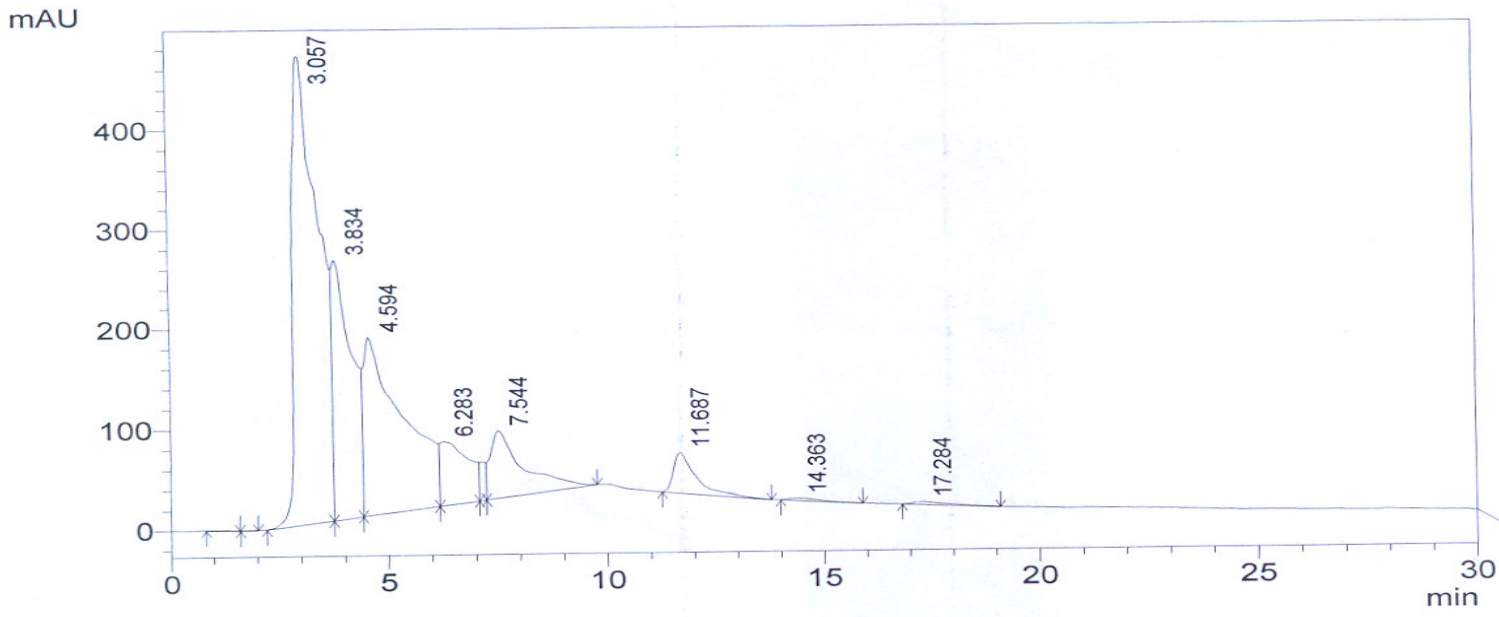

1 PDA Multi $1 / 254 \mathrm{~nm} 4 \mathrm{~nm}$

Figure 2. HPLC spectrum of saponin from O.gratissimum

\section{Discussion}

The result of the work indicates that $0.7 \mathrm{~g}$ of saponin mixed with $70 \%$ methanol was recovered from $40 \mathrm{~g}$ of O.gratissimum leaves. HPLC analysis for saponin extract revealed eight peaks, each with a total elution time of 30 mins. Each peak also eluted at different retention time. The number of peaks present in the methanol extract is more than the number of peaks present in the saponin extract. This shows that saponin was extracted from the methanol mixture which contains other constituents outside saponin; more peaks are contained in the methanol extract. After 7.544 mins, there was a pause in the spectrum of the saponin which has a small peak area. In the methanol extract, small peaks were observed before a sudden rise of 11.530 peak. This shows that there is a mass transfer of saponin compounds from the methanol mixture during the extraction of saponins. Moreover, the number of peaks decreased to eight peaks from fifteen peaks observed in the methanol extracts chromatogram. This justified the concentration of the saponin increased in the saponin fraction. Standard references of saponin were not used. It is expected that we run the saponin standard reference to confirm the compounds and type of saponin present in the sample.

The anti-tuberculosis activity of saponin and synthesized nanoemulsion (emulsifier) of saponin from the leaves of O.gratissimum was carried out on $M$. bovis and $M$. smegmatis. The result shows the improved MIC from $1250 \mu \mathrm{g} / \mathrm{ml}$ to $312.5 \mu \mathrm{g} / \mathrm{ml}$ and $625 \mu \mathrm{g} / \mathrm{ml}$ to $39 \mu \mathrm{g} / \mathrm{ml}$ respectively. The saponin sensitivity of M. bovis has MIC at $1250 \mu \mathrm{g} / \mathrm{ml}$ while M.smegmatis is $625 \mu \mathrm{g} / \mathrm{ml}$. Furthermore, the synthesized saponin nanoemulsion sensitivity of M.bovis has MIC at $312.5 \mu \mathrm{g} / \mathrm{ml}$ while M. smegmatis is $39 \mu \mathrm{g} / \mathrm{ml}$. This shows that M. bovis is more resistant to saponin extract than M. smegmatis. We can observe that M. bovis is also more resistant to emulsifier than that of M. smegmatis. In the above result, we discovered that emulsifier has a better activity against the test organisms than saponin extract. The results of the Anti-tuberculosis activity of the saponin and nanoemulsified saponin of O.gratissimum shows that the extracts have anti-tuberculosis effects on the 2 strains of tuberculosis (M. bovis BCG and M. smegmatis) although at varying concentrations. The saponin had a MIC of $1250 \mu \mathrm{g} / \mathrm{ml}$ against $M$. bovis and MIC of $625 \mu \mathrm{g} / \mathrm{ml}$ against $M$. smegmatis. The activity of the nano emulsified saponin sample increased by 2 and 4 folds with MIC of $312.5 \mu \mathrm{g} / \mathrm{ml}$ against $\mathrm{M}$. bovis BCG and MIC of $39 \mu \mathrm{g} / \mathrm{ml}$ against M. smegmatis

\section{Conclusion}

The methanol extract which was analyzed with HPLC shows resolution which gave 15 peaks while the saponin extract gave rise to 8 peaks. The nanoemulsion was synthesized with $250 \mathrm{mg}$ saponin. The study indicates that the synthesized emulsifier produced from saponin is more effective against tuberculosis test organisms (M. bovis and M. smegmatis) than saponin extract. Nanomedicine has a remarkable prospect in the improvement of diagnosis and treatment of human disease such as tuberculosis. Uses of microbes, plants, etc, in the biosynthesis of nanoproducts are an environmental acceptable procedure. Nanotechnology has turned a wide array of tools in biotechnology so that they are more personalizing, portable, cheaper, safer and easier to administer. Biological method of nanoemulsion and nanoparticles synthesis using microorganism (Klaus, et. al, 1999; Konishi, and Uruga, 2007), enzyme, fungus and plants or plants extracts is an eco-friendly alternative to the chemical and physical method.

\section{References}

International Regulatory Cooperation for Herbal Medicines (IRCH). World Health Organization (2017). 
Nakamura, C.V., Nakamura, T.U., Bando, E., Melo, A.J.N., Cortez, D.A.G., Dias Filho, B.P. (1999), "Antibacterial activity of Ocimum gratissimum essential oil", Mem. Inst. Oswaldo Cruz; 94: 675-678.

Holets, F.B., Ueda-Nakamura, T., Filho B.P.D., Cortez, D.A.G., Morgado-Diaz, J.A., Nakamura, C.V, (2003), "Effect of essential oil of Ocimum gratsimum on the trypanosomatid Herpetomonas samuelpessoai", Act. Protonzool;42: 269-276.

Dubey, N.K., Tiwari, T.N., Mandin, D., Andriamboavonjy, H., Chaumont, J.P., (2000), “Antifungal properties of Ocimum gratissimum essential oil (ethyl cinnamate chemotype)", Fitoterapia; 7(15): 567-569.

Windaus, A., (1909), "Ueber die Entgiftung der saponine durch cholesterin", Ber; 42, 238 - 246.

Hostettmann, K., and Marston, A., (1995). "Saponins", Cambridge University Press UK

Donsì, F., Senatore, B., Huang, Q., and Ferrari, G., (2010), "Development of novel pea protein-based nanoemulsions for delivery of nutraceuticals", J Agric Food Chem.;58(19):10653-60. doi: $10.1021 /$ jf101804g.

Ashish, K., Ankit, G., Ankush. S., and Amrish, (2014), "Nanoemulsion formulation using green synthesised silver nanoparticles using Azadirachta indica leaf extract”, https:/www.researchgate.net/publication/268807326

Ajuru, M.G., Williams, L.F., Ajuru, G., (2017), "Qualitative and Quantitative Phytochemical Screening of Some Plants Used in Ethnomedicine in the Niger Delta Region of Nigeria", Journal of Food and Nutrition Sciences doi: $10.11648 /$ j.jfns.20170505.16

Okhale, S.E., Nnachor, A.C., Bassey, U.E., (2017), "Evaluation of HPLC-UV-DAD and antiproliferative characteristics of the leaf infusion of Ximenia americana Linn.”, MicroMedicine; 5 (2): 45-52)

Klaus, T., Joerger, R., Olsson, E., and Granquist, C.G., (1999), "Silver Based crystalline Nano particles, microbialy fabricated", J. Proc. Natl. Acad. Sci, USA; 96,13611-13614.

Konishi, Y., and Uruga, T., (2007), "Bioreductive Deposition of platinum Nano particles on Bacterium Shewanella algae", J. Biotechnol; 128, 648-653. 